\title{
Dual-Mode Combustion of Hydrogen in a Mach 5, Continuous-Flow Facility
}

\author{
C. P. Goyne, ${ }^{*}$ J. C. McDaniel, ${ }^{\dagger}$ T. M. Quagliaroli, ${ }^{\ddagger}$ R. H. Krauss, ${ }^{\ddagger}$ and S. W. Day ${ }^{\ddagger}$ \\ University of Virginia, Charlottesville, Virginia 22904
}

\begin{abstract}
Results of an experimental and numerical study of a dual-mode scramjet combustor are reported. The experiment consisted of a direct-connect test of a Mach 2 hydrogen-air combustor with a single unswept-ramp fuel injector. The flow stagnation enthalpy simulated a flight Mach number of 5. Measurements were oblained using conventional wall instrumentation and a particle-imaging laser diagnostic lechnique. The particle imaging was enabled through the development of a new apparatus for seeding fine silicon dioxide particles into the combustor fuel stream. Numerical simulations of the combustor were performed using the GASP code. The modeling, and much of the experimental work, focused on the supersonic combustion mode. Reasonable agreement was observed between experimental and numerical wall pressure distributions. However, the numerical model was unable to predict accurately the effects of combustion on the fuel plume size, penetration, shape, and axial growth.
\end{abstract}

\section{Nomenclature}

$H=$ normal height of ramp injector

$M \quad=$ Mach number

$P \quad=$ static pressure

$\operatorname{Pr} \quad=$ Prandtl number

Sc $=$ Schmidt number

$T=$ temperature

$X, Y, Z=$ Cartesian coordinates with origin at ramp base

\section{Subscripts}

$\begin{array}{ll}\text { av } & =\text { average } \\ \text { ref } & =\text { reference quantity at nozzle exit } \\ t & =\text { turbulent }\end{array}$

\section{Introduction}

$\mathbf{T}$ HE concept of a dual-mode scramjet has considerable potential for transatmospheric vehicle applications.' The dual mode of operation provides the capability of using a single-engine flowpath over a broad range of flight Mach numbers. At speeds of Mach 5 and above, the engine is operated as a scramjet, and the heat-release process in the combustor remains predominantly supersonic. At lower speeds however, the requirement of high thermal efficiency prespeeds howe combustion process remain subsonic. ${ }^{2}$ This ramjet scribes that the combustion process remain subsometry, by matchmode can be achieved, using the same engine guch that a ing the flowpath area ratio and combustion heat release such injecthermal choke is produced downstream of the point of this choke tion. Provided the associated pressure rise upstream of this choke can be effectively isolated from the engine's supersonic inet, the dual-mode scramjet will operate at low supersonic fight speeds in a manner similar to a conventional ramjet.

Of particular importance to the development of dual-mode scramjets are the differences in the fuel-air mixing, ignition, and combustion processes in the supersonic and subsonic modes and in the transition region belween the modes. Although the dual-mode concept has been experimentally studied since the $1960 \mathrm{~s},{ }^{1.3}$ these processes and differences are still not fully understond. Modern computational

Teciober 2000: revision reccived 3 January 200)1; accepted

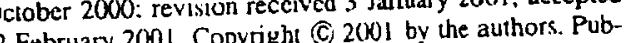
for publication 12 February 2001 . Copyrignt 2 (O) bentics, Inc, with lished by the Ar

permission.

- Research Associate Member AIAA.

t Professor. Senior Member AIAA.

Prof AlAA.

‡Graduate Research Assistant. Stude Research Laboratory, 570 Edgemont Road. fluid dynamics (CFD) can provide further insights into the fundamentals of these combustors; however, numerical and experimental studies must be appropriately coupled through code validation and calibration. As a means of providing this link, an experimental study of a dual-mode combustor has been undertaken. The study is aimed at providing a benchmark data set using conventional instrumentation and nonintrusive laser diagnostics techniques for wall and instream measurements, respectively. This study has been paralleled by numerical modeling of the dual-mode combustor. The simulation is part of an effort (e.g., Ref. 4) that is aimed at finding optimum combinations of CFD codes, grids, and turbulence and chemistry models for the analysis of dual-mode scramjets.

The present contribution reports on results of an experimental arid numerical study of a direct-connect Mach 2 hydrogen-air combustor with a 10-deg unswept-ramp fuel injector. Flow conditions simulated a flight Mach number of 5 . The paper begins by describing the experimental and numerical techniques. Centerplane and crosstfow. results are then presented. In particular, experimental and numerical wall pressure distributions and crossflow fuel plume images are directly compared for the supersonic combustion mode. To investigate the effects of combustion on the fuel-air mixing process, the crossflow fuel plume results are compared in terms of nonreacting fuel-air (mixing only) and reacting fuel-air.

\section{Experimental Technique}

\section{Combuster Conflguration}

A schematic of the combustor configuration is presented in Fig. 1 . The flowpath consisted of a two dimensional Mach 2 nozzle, a short constant-area rectangular isolator, and a rectangular combustion duct. An unswept 10-deg compression ramp injector was located on one of the walls of the combustor (this wall is referred to here as the injection wall). The ramp had a height-to-width ratio of 0.5 and. at its highest point, formed a duct blockage of approximately a . Hydrogen conical nozzle in the ramp base. The centerline of the nozzle was parallel to the ramp 10 -deg surface.

Linear dimensions of the combustor configuration are detailed in Table l. Unless stated otherwise, all linear dimensions reported here are normalized interms of the normal height of the ramp $H$ (perpendicular to the injection wall). The combustion duct was of constant cross-sectional area up to a distance of $10 \mathrm{H}$ downstream of the ramp base. From this point the injection wall had a 2.9-deg divergence. The combustion duct extended to a distance of $58 \mathrm{H}$ from the ramp the combustion duct extended to a do atmosphere as a freejet.

Static pressure taps were located at the nozzle exit, on the ramp face, and along the combustion duct. In relation to the ramp base, 
Table 1 Combustor geometry dimensions

\begin{tabular}{lc}
\hline Feature & Dimension \\
\hline Ramp height & $H=6.4 \mathrm{~mm}$ \\
Isolator height & $4 H$ \\
lsolator width & $6 \mathrm{H}$ \\
Isolator length & $2 \mathrm{H}$ \\
Combustion duct inlet height & $4 \mathrm{H}$ \\
Combustion duct width & $6 \mathrm{H}$ \\
$X$ distance to 2.9-deg surface & $10 \mathrm{H}$ \\
$X$ extent of combustion duct & $58 \mathrm{H}$ \\
Ramp length & $6 \mathrm{H}$ \\
Ramp width & $2 \mathrm{H}$ \\
Ramp compression angle & $10 \mathrm{deg}$ \\
Injector exit Y location & $0.6 \mathrm{H}$ \\
Injector port diameter & $0.4 H$ \\
Injoction angle & $10 \mathrm{deg}$ \\
\hline
\end{tabular}

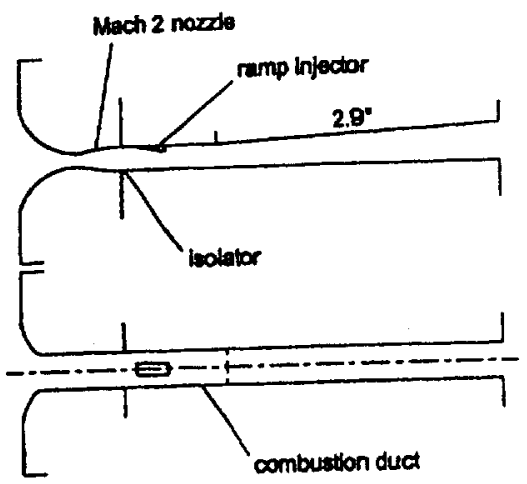

Fie 1 Schematic of combustor configuration.

the taps extended axially from $-7 \mathrm{H}$ to $56 \mathrm{H}$. Except for an offcenterline measurement station at $4 H$, the pressure taps were located along the axis of symmetry of the combustor. The off-axis measurement station consisted of two taps, $1 \mathrm{H}$ each from the duct centerline. The static pressure was measured using a Setra ${ }^{\text {TM }}$ pressure transducer and a Scanivalve operating at a tap scanning frequency near $0.5 \mathrm{~Hz}$. A full pressure scan of the combustor was typically conducted over a $60-s$ period. Type $\mathrm{K}$ thermocouples were located within the injection wall of the combustion duct. These were located on the centerline at $7 \mathrm{H}, 10 \mathrm{H}$, and $22 \mathrm{H}, 0.1 \mathrm{H}$ beneath the wall surface. The experimental uncertainty in wall pressure and temperature measurement was estimated to be $\pm 2 \%$.

Fused silica windows provided optical access on three sides of the combustion duct. The Mach 2 nozzle, window support frames, and portions of the combustion duct were cooled though the use of internal water passages. The isolator, windows, fuel injection ramp, and immediate vicinity around the ramp, however, were not water cooled. From $-8 \mathrm{H}$ to $26 \mathrm{H}$ the injection wall and ramp were zirconia coated.

\section{Facllity and Flow Conditions}

The combustor formed a portion of the Supersonic Combustion Tunnel Facility at the University of Virginia, which is fully described elsewhere. ${ }^{5.6}$ Basically, the overall configuration consisted of an oil-free two-stage compressor, desiccant air dryers, ballast, and air storage tanks, a 14-stage electrical resistance heater, ceramic flow straightener, supersonic nozzle, test combustor, and exhaust tube The facility was capable of continuous operation and provided a flow total temperature near $1200 \mathrm{~K}$. At Mach 2 the test flow static pressure was near $0.4 \mathrm{~atm}$. Unlike vitiated and arc-driven facilities, the electrical heater provided a test gas free of contaminants such as water, NO, particles, and radical species. 3.6

Airflow conditions at the combustor inlet are presented in Table 2. Estimates of the mass flow rate of air through the facility were based on the measured stagnation properties and an assumed facility nozzle discharge coefficient of 0.99 . Fueling conditions are also pre-
Tuble 2 Test cunditions

\begin{tabular}{|c|c|c|c|c|}
\hline arameter & Air & $\begin{array}{l}\text { Fuel } \\
\text { (con. 1) }\end{array}$ & $\begin{array}{l}\text { Fuel } \\
\text { (con. 2) }\end{array}$ & Error \\
\hline Total pressure, $\mathrm{kPa}$ & 330 & 1350 & 1550 & $\pm 3 \%$ \\
\hline Total temperature, $\mathrm{K}$ & 1160 & 460 & 460 & $\pm 3 \%$ \\
\hline Mach number" & 2.1 & 1.7 & 1.7 & \\
\hline Static pressure." kPa & 39 & 270 & 310 & \\
\hline Static temperature, $\mathrm{K}$ & 670 & 290 & 290 & \\
\hline Velocity, ${ }^{2} \mathrm{~m} / \mathrm{s}$ & 1050 & 2200 & 2200 & \\
\hline Equivalence ratio & - & 0.32 & 0.37 & 50 \\
\hline
\end{tabular}

Precombustion property at nozzle exit, calculated using area ratio of nozzle and assuming isentropic fow.

sented in Table 2. Airflow and fuel total conditions were typically maintained to within $2 \%$ of nominal values during a tunnel run. As a means of promoting flame holding, early experiments were conducted with hydrogen electrically heated to a total temperature of $460 \mathrm{~K}$. It was later established that this was unnecessary, and, hence, subsequent tests were performed with a fuel total temperature of $300 \mathrm{~K}$ (with the same equivalence ratio). No significant changes in the combustor wall pressure distributions or flame holding characteristics (e.g., luminescence of flame and injection wall near ramp) were observed. Hence, the effect of this change in fuel total temperature is regarded as minimal in the interpretation of the experimental results. Tests conducted with a fuel total temperature of $300 \mathrm{~K}$ are noted in the text. The mass flow rate of hydrogen was measured using a Hastings ${ }^{T M}$ mass flow meter. Quoted equivalence ratios are, therefore, based on calculated air and measured fuel mass flow rates. As the Mach 2 nozzle exit static temperature was below the fuel autoignition temperature, a hydrogen-oxygen detonation driven igniter system was used for initial ignition of the combustor. Combustion was self-sustaining following ignition.

\section{Crossflow Fuel Plume Imaging}

The crossflow fuel plume images were obtained using a Miescattering technique. ${ }^{7}$ Fine pyrogenic silicon dioxide $\left(\mathrm{SiO}_{2}\right)$ particles were seeded into the hydrogen fuel stream prior to injection into the combustor. The fuel plume, downstream of the ramp fuel injector, was then observed through the scattering of laser light off the seed particles. Silicon dioxide (silica) particles have been used previously for supersonic-mixing Mie-scattering measurements in a low-temperature wind tunnel at the University of Virginia ${ }^{8}$ and for other applications such as planar Doppler velocimetry in compressible jets.9 The seed material used in the present study (Aerosil ${ }^{\circ}$ R812S) was produced by Degussa Corporation and consisted of spherically shaped primary particles with an average diameter of $7 \mathrm{~nm}$. Aerosil is thermally stable up to temperatures near $1500 \mathrm{~K}$. Above this point the silicon dioxide begins to sinter and transform into glass. The particles are hydrophobic and, hence, resist wetting by water; however, the chemical nature of the particles produces agglomerates that are much larger than the primary particle size. Such agglomerates have typical effective diameters of the order of hundreds of microns and must be broken down to smaller diameters to ensure adequate flow tracking. The process of breaking down the agglomerates was achieved, during the fuel seeding process, using a particle shearing method similar to one previously developed.' The process produced particles with effective diameters of $1 \mu \mathrm{m}$ and less. One-micron particles have successfully been used by Ledig et al..$^{8}$ to measure integral mixing efficiency in a nonreacting lowtemperature supersonic fuel plume behind a ramp injector. Injector geometry and flow Mach numbers for the study were of the same order as for the present study. At distances of more than two ramp heights downstream of the fuel injector, Ledig et al. ${ }^{8}$ found that the mixing efficiency determined using these $1-\mu \mathrm{m}$ particles was within $8-129 \%$ of that determined using a planar laser-induced iodine fluorescence (PLIIF) technique. In the PLIIF technique the test flow was seeded with gaseous iodine instead of particles. It is therefore concluded that particle tracking errors will be minimal in the fuel-air mixing observations of the present study. 


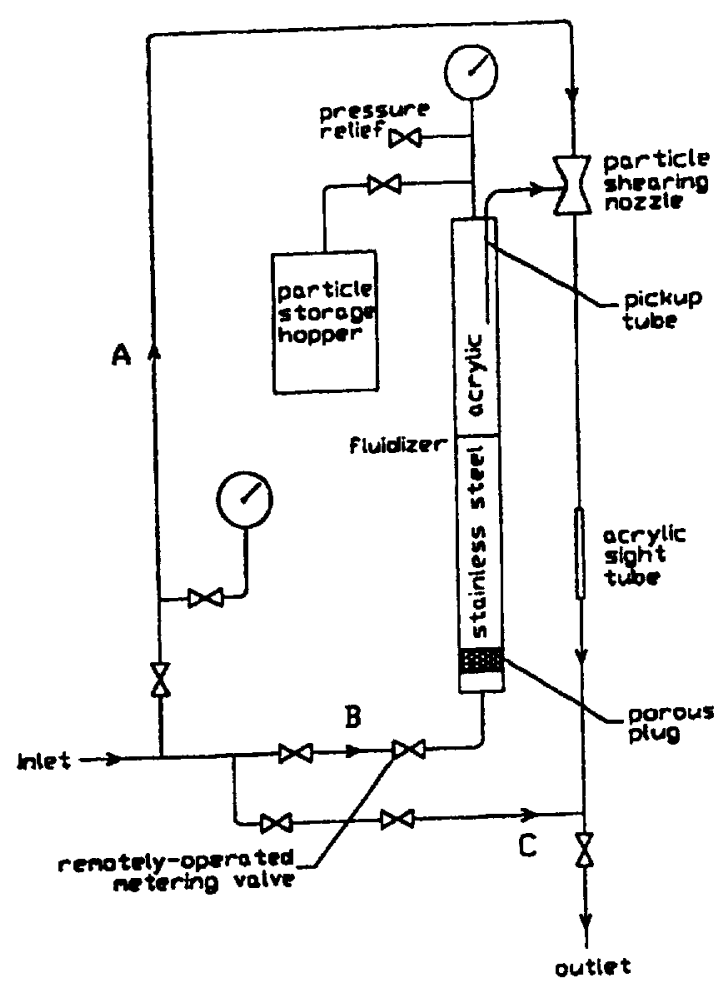

Fig. 2 Fuel seeder schematic (function of flow circuits $A, B$, and $C$ noted in text).

The fuel seeder is schematically presented in Fig. 2. The seeder essentially consisted of a dry fluidized bed hopper (or fluidizer), fine pickup tube, and particle shearing nozzle. The majority of the hydrogen fuel passed through the particle shearing nozzle and to the combustor fuel injector. This flowpath is marked as circuit $A$ in the figure. Fuel fowing through the shearing nozzle was accelerated to Mach 3 and at a point prior to the fuel injector nozzle, shocked back to subsonic flow. A small amount of fuel bypassed the shearing nozzle and was used to fuidize the agglomerated particles in the fluidizing bed hopper (circuit B). Once fluidized, the particles were fed into the shearing nozzle via the pickup tube. The point of injection into the shearing nozzle corresponded to an area ratio at which Mach 2 was attained. The interaction of the transversely injected agglomerated particles with the supersonic fuel stream sheared the agglomerates and dispersed the resulting fine particles into the fuel. The flow rate through the fluidized bed, and hence the seeding rate, was controlled using a remotely operated metering valve. To control the fuel total pressure at the seeder outlet, a small amount of fuel bypassed both the shearing nozzle and fluidizer, and this flowpath is marked as circuit $\mathrm{C}$ in Fig. 2.

Figure 3 presents the optics configuration used for the present fuel plume imaging technique. A laser sheet, with a height of $2.7 \mathrm{H}$ fuel plume imaging lecs than $1 \mathrm{~mm}$, was introduced through one of the side windows of the combustion duct. The Mie scattered light was collected using a TSI Incorporated, 8 bit $1000 \times 1016$ light warge-coupled device camera. Referring to the coordinate artay charge-coupled fig. 3, the laser sheet was orientated in the $Y Z$ system presented in Fig. 3, homed in the $X Z$ plane. The camera plane, while the camera was through one of the side windows, and observed the scancer was mounted with a 45 - $-\mathrm{deg}$ viewing angle. The laser light was supplied by a Nd:YAG pulsed laser with an output of $532 \mathrm{~nm}$ and a pulse rate of $10 \mathrm{~Hz}$. The laser teniporalpulse width was $7 \mathrm{~ns}$. The camera exposure rate was synchronized with the laser such that one laser pulse was captured per exposure. Fifty images were typically captured at each axial location in the combustor Measurements were obtained at planes of $3 \mathrm{H}, 5 \mathrm{H}$, and $7 H$ downstream of the ramp injector base. The $7 H$ plane represented the downstream limit of optical access. Each set of 50 images were averaged to produce an image of the mean crossfow fuel plume. The

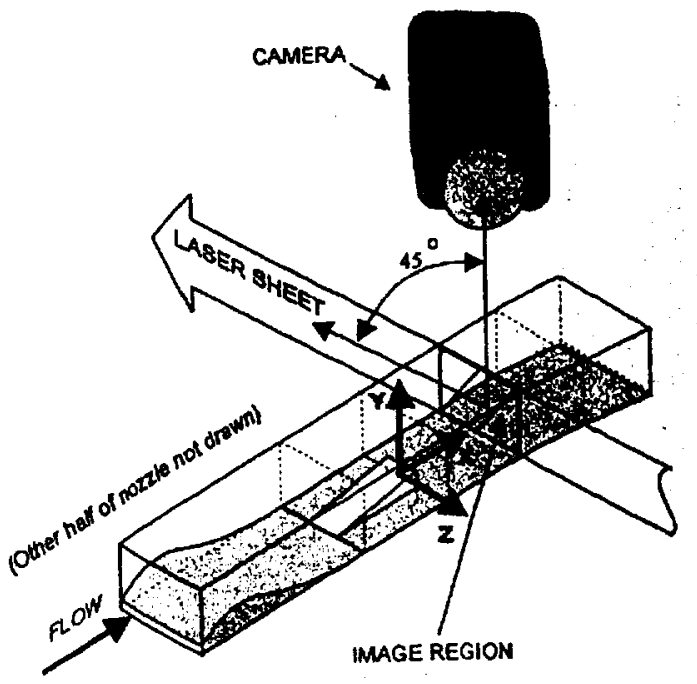

Fig. 3 Fuel plume imaging configuration.

images were background subtracted after averaging and were then geometrically corrected to account for the camera 45-deg viewing angle. The plume images were not compensated for variations in the intensity of the laser sheet or variations in seeding, and, hence, the processed images could not be used to determine absolute injectant density distributions.

\section{Numerical Technique}

The combustor was numerically modeled using the GASPex $~>3.2$ code. ${ }^{10}$ The code was a finite volume, upwind type that was capable of solving the complete set of Reynolds-averaged Navier-Stokes equations. For the present calculations thin-layer Navier-Stokes equations were solved. The code had a variety of inviscid-flux, turbulence, and chemistry models and time-integration schemes. The following combination was used for the present study: 1 ) inviscid fluxes: Van-Leer's flux-vector splitting; 2) turbulence model: Wilcox $k-\omega$ model ${ }^{\prime \prime}$ with $P r_{t}=0.90$ and $S c_{t}=0.5 ; 3$ ) chemistry model: one-step $\mathrm{H}_{2}$-air (simplified chemistry model required to maintain flame holding); and 4) time-integration scheme: three-factor approximate factorization.

The numerical modeling has concentrated on fueling condition 1 The experimental data indicated that the combustor Mach 2 nozzle remained started for this fueling condition, and hence infiguration was solved in two steps: a solution was first the overall confuration were generated for the Mach 2 nozzle, and he nozzle exit conditions of the then used as inlet boundary conditions to the bumer. Because or only symmetry of the configuration, a solution was generated for with a half of the burner. The fuel-injector port was also modeled

square cross section (in order to simplify grid generation).

The experimental measurements indicated that the temperatur $10 \%$ the water-cooled injection wall spatially varied by no more than wall between $7 \mathrm{H}$ and $22 \mathrm{H}$ during combustion. Hence, the injection wean was treated as isothermal downstream of the ramp base, with a nozzle measured temperature of $539 \mathrm{~K}$. As the walls between the noazle exit and ramp injector base were not water cooled, these we $539 \mathrm{~K}$. pected to be at a temperature considerably elevated above s3g Hence, in the absence of temperature measurements in this regich the walls were assumed to be adiabatic. The remaining walls, which from $-6 \mathrm{H}$ to $23 \mathrm{H}$ predominantly consisted of noncooled glass windows, were also assumed adiabatic. Each of the walls we
treated as no slip.

The combustion duct exited to atmosphere as a freejet, and hence, a boundary condition of subsonic flow at a pressure of 1 atm fow field imposed at the downstream end of the duct. Once the basic folution was was obtained using a coarse 47,000 node grid. the final solution wations obtained using a finer grid with 350,000 nodes. The calculations were performed on a SGI R10000 works was lypically attained in 2000 iterations. 


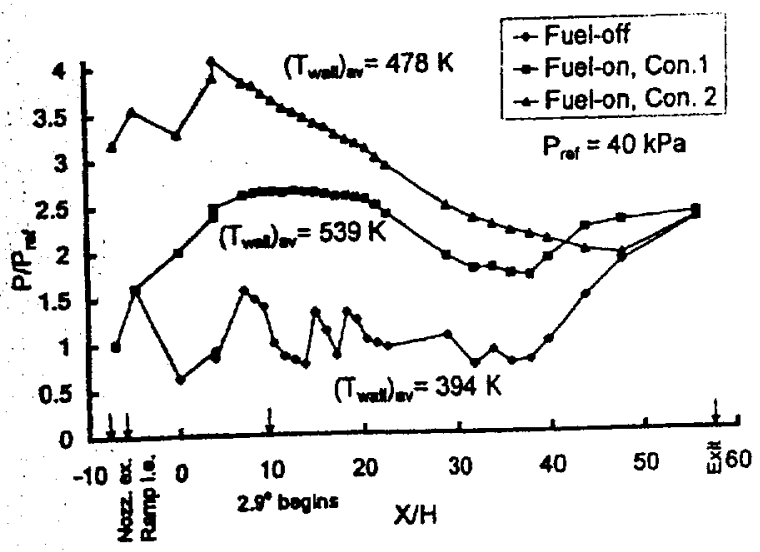

Fig 4 Typical measured wall pressure distributions.

\section{Results and Discussion}

\section{Centerplane}

Measured wall pressure distributions for the fuel-off case and the two fuel-on conditions are presented in Fig. 4. The values have been normalized by the measured fuel-off Mach 2 nozzle exit static pressure, $40 \mathrm{kPa}$, and are presented as a function of distance from the ramp base. For the fuel-off case, a pressure rise behind the rampinduced shock can be observed near $-5 H$. The pressure then falls to almost 0.5 the nozzle exit pressure at the ramp base. Downstream of the base, significant variations in the streamwise pressure distribution are evident. These variations are attributed to shocks and expansion waves associated with the presence of the ramp injector. Downstream of $40 \mathrm{H}$, a rise in wall pressure to the atmospheric exit condition is also clearly evident. The average injection wall temperature, as measured by the three wall thermocouples, was $394 \mathrm{~K}$ for this case. When fuel was injected into the combustor but not manually ignited, the axial pressure distribution was similar to that displayed for the present fuel-off case.

Referring again to Fig. 4, combustion produces a significant rise in the combustor wall pressures for both fuel-on conditions. For condition 1 , with an equivalence ratio of 0.32 , it can be observed that the pressure at the base of the ramp increases to three times the fuel-off value. However, the pressure on the ramp face (near $-5 H)$ is the same as the fuel-off value. This indicates that the ramp-induced shock remains attached and that the combustion process is exerting little or no influence upstream of the ramp base. The inflow at the plane of the ramp leading edge, therefore, is supersonic, and the combustor is operating in the supersonic mode. Between $7 \mathrm{H}$ and $20 \mathrm{H}$ downstream of the ramp base, it can be seen that the wall static pressure is relatively constant. The absence of significant variations in the pressure distribution in this region indicates the existence of a subsonic zone adjacent to the wall.

An increase in the equivalence ratio of only $16 \%$, to fuel condition 2, produces a significant change in the streamwise pressure distribution within the combustor. A ramp base pressure of five times the fuel-off value is reached, and this is immediately followed downstream (at $4 \mathrm{H}$ ) by a peak combustor pressure of four times the fuel-off nozzle exit pressure. A marked influence upstream of the ramp base is also evident at $-5 H$ and $-7 H$. This upstream influence, coupled with the high combustor pressures, is indicative of subsonic inflow to the combustion duct and the attainment of the subsonic mode of operation. The significant increase in nozzle exit pressure, at $-7 \mathrm{H}$, indicates that the isolator was unable to contain the pressure rise upstream of the thermally induced choke within the combustion duct.

The numerically predicted centerplane properties for combustion at fueling condition $\perp$ are now briefly discussed. A comparison of the numerical and experimental wall pressure distributions is shown in Fig. 5. The gross characteristics of the two curves are similar. However, the numerical model fails to predict the plateau in pressure between $7 \mathrm{H}$ and $20 \mathrm{H}$. A distinct peak in pressure is predicted at $-1 H$; however, this cannot be compared with experiment

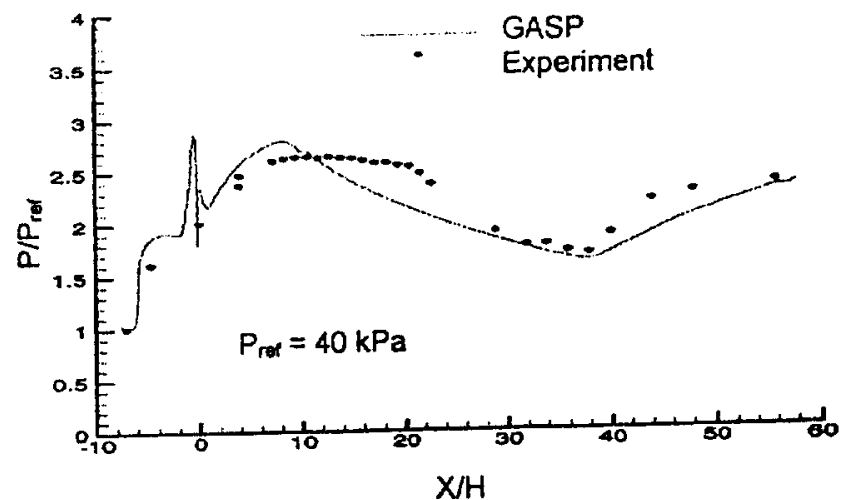

Fig. 5 Comparison of GASP predicted and measured wall pressure distribution for fuel condition 1 .

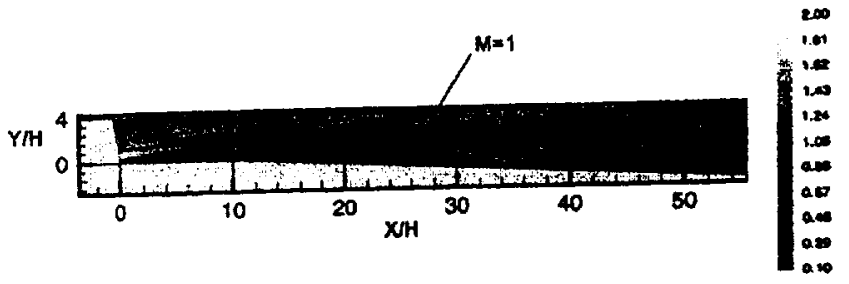

Fig. 6 Numerical centerplane Mach-number contours for fuel condition 1 .

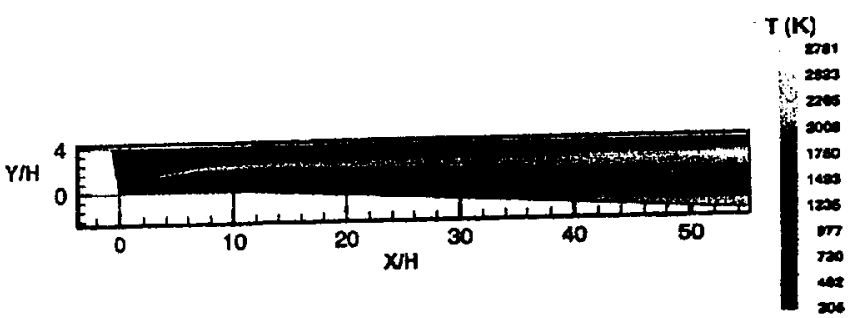

Fig. 7 Numerical centerplane static temperature contours for fuel condition 1.

because of the coarse resolution in the static pressure taps near the ramp.

Predicted Mach-number and static temperature contours are shown in Figs. 6 and 7, respectively. For the Mach-number contour plot the Mach 1 contour is highlighted. The Mach-number plot indicates that a significant portion of the flow near the injection wall, downstream of the fuel injector, remains subsonic. This is consistent with experimental observations. The plot also shows that a core region of supersonic flow is predicted to axially extend along the duct, adjacent to the injector mixing and combustion wake. Referring to the static temperature contour plot, it is evident that, except for the $30 \mathrm{H}$ to $38 \mathrm{H}$ region, these predicted subsonic and supersonic regions are separated by a zone containing the highest temperatures on the centerplane of the combustion duct.

\section{Crossflow}

Crossflow fuel plume images were obtained for the cases of hydrogen-air mixing (with fuel flow but prior to manual ignition) and hydrogen-air reacting (post manual ignition). The images were only obtained for the supersonic combustion mode because of fuel system pressure rating limitations imposed through the use of the seeding apparatus. The measurements were also performed with a fuel total temperature of $300 \mathrm{~K}$. Experimental images for the mixing case are presented in Fig. 8. It can be seen that the fuel plume displays the "kidney" shape that is typical of the mixing wake of unswept supersonic ramp injectors. ${ }^{12}$ This shape is produced by the interaction of ramp-induced counter-rotating vortices with the fuel jet. Also presented in Fig. 8 are numerically predicted 
Experimental

$$
X / H=7
$$

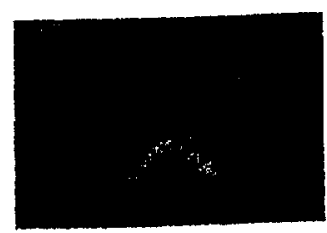

$\mathrm{X} / \mathrm{H}=5$
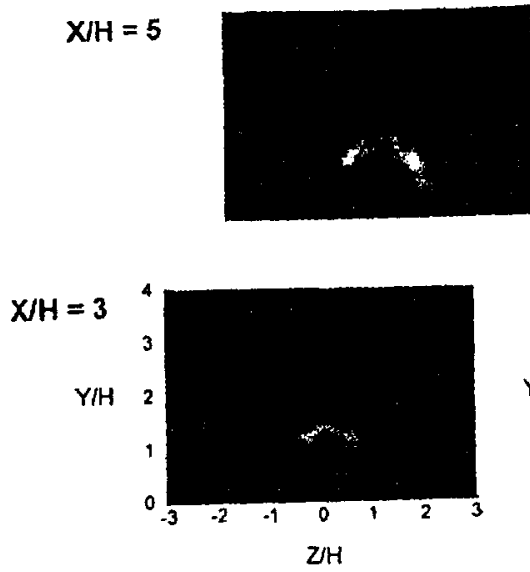

Fig. 8 Crussflow fuel plume images, mixing hydrogen-air (fuel condition 1).
Experimental

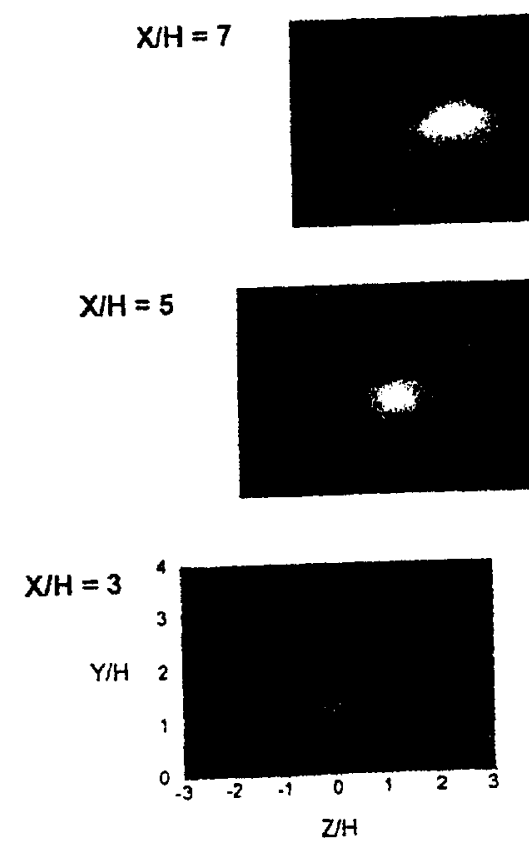

\section{Computational}
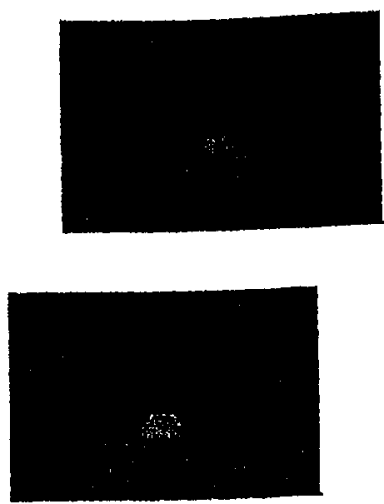

Total

hyorogen

(nomalized)

[atom/m]

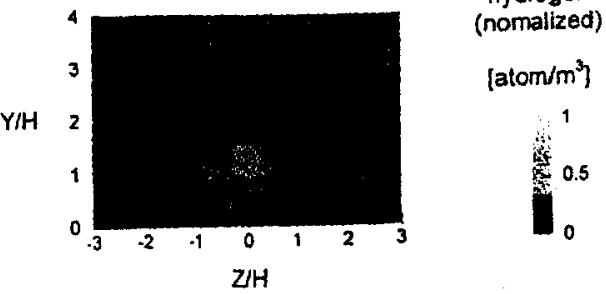

Computational
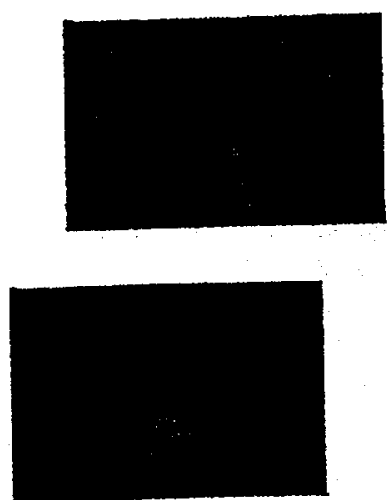

Total

hydrogen

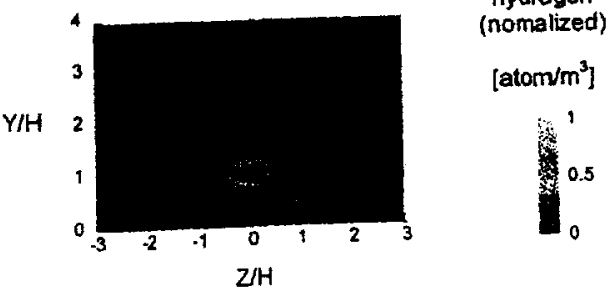

[atom/m]

Fig. 9 Crossflow fuel plume irnages, reacting hydrogen-air (fuel condition 1).

distributions of total hydrogen atom concentration (the sum of hydrogen atoms in the form of $\mathrm{H}_{2}$ and $\mathrm{H}_{2} \mathrm{O}$ that, in the experiment, are effectively "tagged" by the seed particles). Although the numerical results contain concentration information that the experimental data do not, both sets can still be compared to deterinine differences in the fuel plume shape and other mixing performance parameters. Notwithstanding the square cross section that is evipant in the core of the numerically predicted fuel plume (which results from the square fuel injector port in the numerical model), distinct differences are apparent in the plume shapes at the $3 \mathrm{H}$ and $5 H$ planes; however, by $7 H$ the numerically predicted plume is approaching the form experimentally observed. Although there is a lack of agrcement in plume shape, the overall extent of fuel-air mixing and plume penetration (into the flow and away from the injection wall) is similar for experiment and CFD (if not slightly smaller for experiment).

Fuel plume images for the hydrogen-air reacting case are presented in Fig. 9. Comparison of the experimental images with those for the mixing case, Fig. 8, shows that the fuel plume size, penetration, and shape are clearly affected by the combustion process. The plume size and penetration are generally greater, and the lack of the distinct kidney profile in the reacting images indicates that relative to the mixing case, the effects of the ramp-induced vortices on the fuel plume shape are diminished when combustion takes place. Figure 9 also presents the numerical prediction of total hydrogen atom concentration distributions for hydrogen-air reacting. It can be observed that the numerically predicted fuel plume size and penetration are generally smaller than for experiment and the 


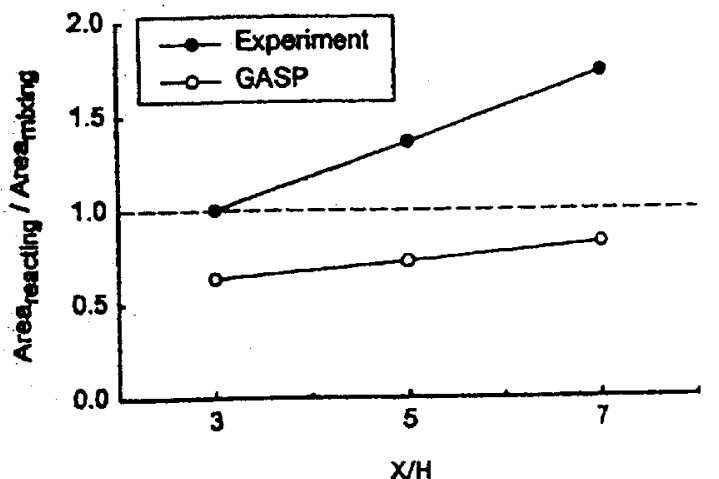

Fig. 10 Fued plume cross-sectional area ratio for experiment and CFD.

distinct lobes in the numerical fuel plumes are not present in the experimental results.

As a means of quantifying the differences between experiment and $\mathrm{CFD}$, the cross-sectional area of the mixing and reacting plumes was determined using the images in Figs. 8 and 9. The location of the boundary of the experimental plumes was determined by thresholding to $20 \%$ of the peak intensity in each plume. Thresholding to a lower level was not possible because of the level of background scatter in the images. For the numerical results the boundary of the plume was defined as the point where total hydrogen atom concentration reached $20 \%$ of the peak level present in each pluine. As a means of accounting for the arbitrary nature of these boundary definitions, the cross-sectional area of the reacting plume was normalized by the area of the mixing plume at each measurement plane. This was conducted separately for the experimental and numerical images. Normalization of the areas in this way allowed the experimental and numerical results to be directly compared. The fuel plume area ratios are presented in Fig. 10, as a function of distance from the point of fuel injection, for both experiment and CFD. The experimental results show that the reacting hydrogen-air plume is the same size as the mixing hydrogen-air plume at an $X / H$ of 3 . The plume is then larger, downstream of $X / H$ of 3 , as the influences of the combustion process become stronger. It is evident that the numerical model predicts a smaller plume for the reacting case telative to the mixing case for each of the measurement planes. This is contrary to the experimental observations, and the result serves whighlight the deficiencies of the numerical model. Comparing the slope of the experimental and numerical curves, it can further be seen that the combustion process has a greater effect on the relative downstream growth of the fuel plume than is numerically predicted. Although the sample size is small, the experimental and numerical results both show strong linear urends over the region of interest.

\section{Conclusion}

Results of an experimental and numerical study of a dual-mode combustor are presented. The experimental component of the study was conducted in a high-enthalpy, clean-air, continuous-flow facility. The stagnation enthalpy of the test flow simulated a flight speed of Mach 5. The experiment consisted of a direct-connect test of a Mach 2 hydrogen-air combustor with a single 10 -deg unswept-ramp fuel injector. The numerical component of the study was conducted using the GASP code.

Measured wall pressure distributions provided evidence of the supersonic and subsonic modes of combustion. For the supersonic mode the numerically predicted axial pressure distribution in the combustor generally matched that of experiment. Both the experimental and numerical results indicated that a broad region of subsonic flow existed within the supersonic main stream. Crossflow fuel plume images for hydrogen-air mixing and reacting were also experimentally and numerically obtained for the supersonic mode of combustion. The experimental plume imaging was enabled through the development of a new apparatus for seeding the hydrogen fuel with fine silicon dioxide particles. For the region of the combustor in wisch the optical measurements were obtained, the numerical model was generally capable of matching the fuel-air mixing if cumbustion was precluded. When the heat release of combustion was incorporated into the model, however, the changes in the fuel plume size, penetration, shape, and axial growth did not match those observed in the experiment.

The experimental results reveal that the ramp-induced vortices and the heat release of combustion dominate the characteristics of the fuel-air plume. The numerical model adequately matched the extent of fuel-air mixing when combustion was precluded and, hence, exhibited a capability of adequately simulating the effect of the vortices on the fuel-air plume. However, the model failed to incorporate accurately the effect of heat release when combustion took place. This points to deficiencies in the interaction of the chemistry model with the remainder of the code, in particular the turbulence model. Alternate numerical models can be explored in an effort to improve agreement; however, additional experiments are recommended in order to gain further insight into the physical processes and provide a guide as to where the numerical effort should be focused. The authors are currently applying the fuel seeding apparatus to the measurement of velocity in the dual-mode combustor using particle image velocimetry (Ref. 13 describes the technique). Velocity measurements have been obtained in the fuel-air plume along the centerplane of the combustor, for both the reacting and nonreacting cases, and measurements in crossflow planes are proposed. Crossflow velocity measurements, in particular, would enable the strength of the ramp-induced vortices to be quantitatively compared for the mixing and reacting cases. Hence, for the combusting fuel plume, which is presently poorly modeled, the extent of vortex effects, relative to heat release effects, could be further investigated.

\section{Acknowledgments}

This research was sponsored by NASA and the U.S. Air Force through Grants NAG-1-2085 and NAG-1-2131. C. R. McClinton and D. E. Reubush of the NASA Langley Research Center contributed as technical monitors. The authors also gratefully acknowledge C. G. Rodriguez of the National Research Council, Hampton, VA, for performing the GASP numerical simulations.

\section{References}

'Billig, F. S., "Research on Supersonic Combustion," Journal of Propulsion and Power. Vol. 9. No. 4, 1993, pp. 499-514.

${ }^{2}$ Heiser. W. H.. and Prall. D. T., Hypersonic Airbreathing Propulsion, AIAA Education Series, AIAA, Washington, DC, 1994, p. 334.

${ }^{3}$ Rogers, R. C.. Capriotti, D. P., and Guy, R. W., "Experimental Supersonic Combustion Rescarch at NASA Langley," AIAA Paper 98-2506. June 1998.

"Rodriguez, C. G., White, J. A., and Riggins. D. W., "Three-Dimensional Effects in Modeling of Dual-Mode Scramjets," AIAA Paper 2000-3704, July 2000.

${ }^{5}$ Krauss, R. H., McDaniel, J. C., Scott, J. E., Whitehurst, R. B., Segal, C. Mahoney, G. T., and Childers, J. M.. "Unique, Clean-Air, ContinuousFlow, Higli-Stagnation-Temperature Facility for Supersonic Combustion Research," AIAA Paper 88-3059, July 1988.

${ }^{6}$ Krauss, R. H., and McDaniel, J. C., "A. Clean Air Continuous Flow Propulsion Facility," ALAA Paper 92-3912, July 1992.

Meyers, J. F., "Generation of Particles and Seeding," von Karman Inst. for Fluid Dynamics, Laser Velocimetry Lecture Series 1991-08, Rhode-St. Genese. Belgium. June 1991.

${ }^{8}$ Ledig, S. H., Donohue, J. M., and McDaniel, J. C.. "Mie Scattering for Mixing Measurements in Nonreacting Supersonic Flowfields," 3 Ist AIAAV ASME/SAE/ASEE Joint Propulsion Conference and Exhibit, July 1995.

${ }^{9}$ Smith. M. W. "Application of a Planar Doppler Velocimetry System to a High Reynulds Number Compressible Jet," AlAA Paper 98-0428, Jan. 1998. 10 Aerosoft. Inc., "GASPex Version 3-User's Manual;" Blacksburg, VA, March 1997.

"Wilcox. D.. "Comparison of Two-Equation Turbulence Models for Boundary Layers with Pressure Gradient," AlAA Journal, Vol. 31, No. 8, 1993 , pp. 1414-1421.

12Donohue, J. M., and McDaniel, J. C., "Complete Three-Dimensional Multiparameter Mapping of a Supersonic Ramp Fuel Injector Flowtield," AlAA Sournal. Vol. 34, No. 3, 1996, pp. 455-462.

${ }_{13}$ Raffel, M., Willert, C. E., and Kompenhans, J., "Particle lmage Velocimetry. A Practical Guide." Experimental Fluid Mechanics, edited by R. J. Adrian, M. Gharib. W. Merzkirch, D. Rockwell, and J. H. Whitelaw. Springer-Verlag. Berlin, 1998, p. 3. 